\title{
An EPQ Model under Constant Amelioration, Different Deteriorations with Exponential Demand Rate and Completely Backlogged Shortages
}

\author{
P. D. Khatri ${ }^{1 *}$, U.B.Gothi ${ }^{2}$ \\ ${ }^{1 *}$ K.S. School of Business Management, Gujarat University, Ahmedabad, India \\ ${ }^{2}$ Department of Statistics, St.Xavier's College (Autonomous), Ahmedabad, India \\ *Corresponding Author:pooja.khatri25491@gmail.com,Tel: +91 8306868929
}

Available online at: www.isroset.org

Received 16/Mar/2018, Revised 22/Mar/2018, Accepted 14/Apr/2018, Online 30/Apr/2018

\begin{abstract}
In the present paper, we have developed an economic production quantity inventory model for ameliorating and deteriorating items. At the inception of production activity, the constant amelioration, two parameter Weibully distributed deterioration rate and exponential demand rate have been considered At the conclusion stage of production activity, deterioration of items has been assumed to follow Pareto Type-I distribution with the same amelioration and demand rate as at the inception stage. The time dependent inventory holding cost is assumed to be a linear function of time. Shortages are acceptable and backlogged completely. The aim of this study is to find the optimal solution for minimizing the total inventory cost. The manifest the model, a numerical illustration has been presented along with a sensitivity analysis for studying the impact of parameters on assessment variables and total cost of the model.
\end{abstract}

Keywords: Weibull distribution, Pareto type - I distribution, Amelioration rate

\section{INTRODUCTION}

Several published theses have addressed the importance of the deterioration phenomenon in field applications; as a result, many deterioration models have been consequently developed. Yet we have not observed much appreciation of ameliorating consideration. Due to lack of consideration for the influence of demand, the ameliorating items assuming duration for the amount of inventory will gradually increase; meanwhile, in the traditional inventory model dealing with deteriorating items, the amount of inventory will gradually decrease. Among the published literatures, scholars and researchers have not pay much attention to the ameliorating problems and items. To cope with this deficiency, lately a few studies are concerned with the problems of amelioration, because they do exist in the real world such as the farming, fishery, and poultry industries. The fast growing animals like ducks, pigs, and broilers in poultry farms, highbred fishes in ponds, and the cultivation of vegetables and fruits in farms are typical field applications. This is quite different from the deteriorating items and deserves a comprehensive study. Weibull distribution has been used to address the problems of product life cycle in recent years due to its capacity to effectively describe various product life spans by imbibing the variations in parameters' value. Inventory models for ameliorating and deteriorating items are applicable when the effects of deterioration and amelioration occur simultaneously. Such inventory models are for items like fruits, vegetables, flowers and some dairy products where the combined effect of amelioration and deterioration is observed.

Hwang [5] is likely to have initiated the study of inventory systems comprising both ameliorating and deteriorating items where he assumed that items ameliorate at a breeding yard, such as aquaculture facilities and deteriorate at distribution centres. Law and Wee [14] have studied the EPQ model with ameliorating and deteriorating items by allowing shortages along with time discounting and integrating the manufacturer-retail co-operation. L.Tadj et al.[8] have also done a similar study on production inventory model with both ameliorating and deteriorating items.

Lan, Yu, Lin, Tung, Yen and Deng [3] have depicted a study on an enriched algebraic method for the EPQ model with stochastic lead time. Shamsi, Haji, Shadrokh and Nourbakhsh [13] published their study on EPQ in reworkable production systems including inspection errors, scraps and backlogging. Jain, Sharma and Rathore [9] have presented an EPQ model with involvement of shortage, 
price and stock dependent demand for deteriorating items. Integrated inventory models for decaying items with exponential demand under inflation have been given by Bansal and Ahalawat [6]. Kawale and Bansode [7] have published an EPQ model using Weibull distribution for deterioration items along with time varying holding cost. Gothi, Shah and Khatri [16] recently developed two warehouses inventory model for deteriorating items with power demand and time varying holding cost where shortages are permissible and are a mixture of partial backlog and lost sales. Parmar and Gothi [11] have developed an EPQ model for deteriorating items assuming three parameter Weibull distribution with constant production rate and time-varying holding cost. Also Kirtan Parmar and U.B.Gothi [10] have presented an EPQ model for deteriorating items under three parameter Weibull distribution and time dependent inventory holding cost with shortages. Mishra, Raju, U.K. Misra and G. Misra [15] have presented their study on optimal control of an inventory system consisting of variable demand and ameliorating/deteriorating demand. Inventory Models for both ameliorating and deteriorating items have also been presented by Ankit Bhojak and U. B. Gothi [1] and [2]. Pooja D. Khatri and U.B.Gothi [12] have recently published an inventory system for deteriorating items having power demand pattern and time-dependent inventory holding cost. An EPQ model for deteriorating items following two parameter Weibull distribution along with exponential demand rate has been presented by Devyani Chatterji and U. B. Gothi [4].

In the present paper, we have redeveloped the above inventory model by considering an EPQ model with constant amelioration rate and demand following exponential pattern. For different time periods, Weibull and Pareto Type-I distribution with two parameters are considered for the deterioration rate. We employ Weibull distribution because it is widely used in reliability and survival analysis and Pareto Type-1 Distribution because it helps test severity of large casualty losses for certain lines of business. In this model shortages are allowed to occur and they are completely backlogged. In this model inventory holding cost is time dependent and a linear function of time while production rate is more than demand rate. Numerical illustration and sensitivity analysis presented here have been carried out by varying the parameter values one after the other.

\section{ASSUMPTIONS}

For development of the model, below mentioned assumptions have been considered:

1. The inventory system comprises of only one item and one stocking point.

2. Replenishment rate for the item is infinite and there is no lead time.

3. As soon as a unit is produced, it is available to satisfy the demand.

4. Holding cost is a linear function of time and it is $C_{h}=h+r t(h, r>0)$.

5. Item deteriorates or ameliorates only when it is effectively in stock.

6. The annual demand rate is an exponential function of time and it is $R(t)=a e^{\lambda t}$.

7. Amelioration rate $A(t)=\theta_{1}$ is constant which is derived from exponential distribution.

8. The deterioration rate is given by

$$
=\left\{\begin{array}{cc}
\alpha \beta t^{\beta-1} & ; 0 \leq t \leq \mu \\
\frac{\theta}{t} & ; \mu \leq t \leq t_{1}
\end{array}\right.
$$

where $\alpha$ is scale parameter $(0<\alpha \ll 1), \beta$ is shape parameter $(\beta>0), \theta$ and $\mu$ are parameters of Pareto type-I distribution taking positive real values.

9. Shortages are allowed and they are fully backlogged.

10. The second and higher power of $\alpha$ and $\theta$ are neglected in the analysis of the derived model.

11. Per unit cost for amelioration, deterioration, production, ordering and shortage are known and constant.

12. Total cost for the inventory is a real and continuous function, bowed to the origin.

\section{NOTATIONS}

The following notations are used to develop the model:

1. $Q(t)$ : Instantaneous rate of the Inventory level at any time

$$
t(0 \leq t \leq T)
$$

2. $R(t)$ : Demand rate varying over time.

3. $\theta(t)$ : Deterioration rate.

4. $A(t):$ Amelioration rate.

5. $p$ : Production rate. 
6. $a$ : Initial rate of demand.

7. $A$ : Ordering cost per order during the cycle period.

8. $C_{d}$ : Deterioration cost per unit.

9. $C_{h}$ : Inventory holding cost per unit per unit time.

10. $C_{s}$ : Shortage cost per unit.

11. $C_{p}$ : Production cost per unit. $\left(C_{p}>C_{a}\right)$

12. $C_{a}$ : Amelioration cost per unit.

13. $S_{1}$ : Maximum inventory level at time $t=\mu$.

14. $S_{2}$ : Maximum inventory level during the shortage period at $t=t_{2}$.

15. $t_{1}$ : Time at which shortages start, $\mu \leq t_{1} \leq T$.

16. $T$ : Length of the replenishment cycle.

17. TC: The average total cost for the time period $[0, T]$.

\section{MATHEMATICAL FORMULATION AND SOLUTION}

At the inception stage, inventory level is nil. At time $t=0$, production and supply start simultaneously but the production stops at $t=\mu$ when the maximum inventory level $S_{1}$ is achieved. During the span $[0, \mu]$, the inventory is produced at a rate $p$. In spite of a constant amelioration rate existing in time interval $\left[\mu, t_{1}\right]$, the stock reaches to zero level at time $t=t_{1}$ because of the demand rate $a e^{\lambda t}$ and the Pareto type-I deterioration rate of $\frac{\theta}{t}$. Thereafter, shortages are allowed to occur during the time interval $\left[t_{1}, t_{2}\right]$ at a rate $a e^{\lambda t}$. Post that, time interval $\left[t_{1}, t_{2}\right]$ allows shortages at a rate $a e^{\lambda t}$. At time $t=t_{2}$, the maximum level $S_{2}$ for shortage is attained, causing production to resume at the same rate and the backlog is cleared in the time interval $\left[t_{2}, T\right]$. The stock level becomes nil at time $t=T$. The same cycle is repeated and observed for the further time period $T$

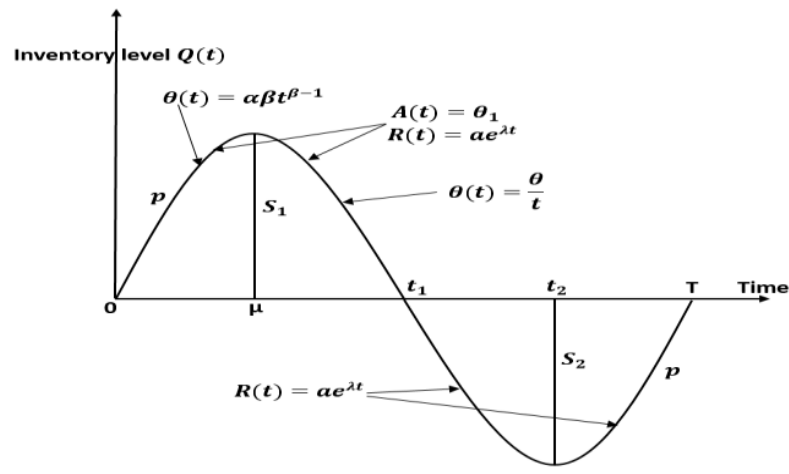

Fig. 1. Graphical rendition of Inventory System
The differential equations describing the instantaneous state of $Q(t)$ over the period $[0, \mathrm{~T}]$ are given by

$$
\begin{array}{ll}
\frac{d Q(t)}{d t}+\alpha \beta t^{\beta-1} Q(t)=\theta_{1} Q(t)+p-a e^{\lambda t} & 0 \leq t \leq \mu \\
\frac{d Q(t)}{d t}+\frac{\theta}{t} Q(t)=\theta_{1} Q(t)-a e^{\lambda t} & \mu \leq t \leq t_{1} \\
\frac{d Q(t)}{d t}=-a e^{\lambda t} & t_{1} \leq t \leq t_{2} \\
\frac{d Q(t)}{d t}=p-a e^{\lambda t} & t_{2} \leq t \leq T
\end{array}
$$

Using the boundary conditions $Q(\mu)=S_{1}$, and $Q\left(t_{2}\right)=-S_{2}$ the solutions of above four equations are given by

$$
\begin{aligned}
& Q(t)=(p-a) t+\left\{(p-a) \theta_{1}+a \lambda\right\} \frac{t^{2}}{2}-\frac{(p-a) \alpha \beta}{\beta+1} t^{\beta+1} \\
& Q(t)=-a\left[\begin{array}{l}
\frac{1}{\theta+1}\left(t-t_{1}^{\theta+1} t^{-\theta}\right)+\frac{\lambda-\theta_{1}}{\theta+2}\left(t^{2}-t_{1}^{\theta+2} t^{-\theta}\right)+ \\
\frac{\theta_{1}}{\theta+1}\left(t^{2}-t_{1}^{\theta+1} t^{1-\theta}\right)+\frac{\lambda-\theta_{1}}{\theta+2} \theta_{1}\left(t^{3}-t_{1}^{\theta+2} t^{1-\theta}\right)
\end{array}\right] \\
& Q(t)=-a\left[\left(t-t_{1}\right)+\frac{\lambda}{2}\left(t^{2}-t_{1}^{2}\right)\right] \\
& Q(t)=(p-a)(t-T)-\frac{a \lambda}{2}\left(t^{2}-T^{2}\right)
\end{aligned}
$$

Substituting $Q(\mu)=S_{1}$ in equation (5), we get

$$
S_{1}=(p-a) \mu+\left\{(p-a) \theta_{1}+a \lambda\right\} \frac{\mu^{2}}{2}-\frac{(p-a) \alpha \beta}{\beta+1} \mu^{\beta+1}
$$

Substituting $Q\left(t_{2}\right)=-S_{2}$ in equation (7) and (8), we get

$$
\begin{aligned}
& S_{2}=a\left[\left(t_{2}-t_{1}\right)+\frac{\lambda}{2}\left(t_{2}^{2}-t_{1}^{2}\right)\right] \\
& S_{2}=(p-a)\left(T-t_{2}\right)-\frac{a \lambda}{2}\left(T^{2}-t_{2}^{2}\right)
\end{aligned}
$$

From equations (10) and (11), we get

$t_{2}=\frac{1}{p}\left[a t_{1}+\frac{a \lambda}{2}\left(t_{1}^{2}-T^{2}\right)+(p-a) T\right]$

Therefore, as $t_{2}$ can be expressed in terms of $t_{1}$ and $\mathrm{T}$, it is not taken as a decision variable. 


\section{COST COMPONENTS}

Considering the aforementioned model description and underlying assumptions, the total cost is made up of following components:

\section{(1) Ordering Cost (OC)}

The operating cost over the period $[0, T]$ is $O C=A$

\section{(2) Deterioration Cost (DC)}

The deterioration cost during the period $\left[0, t_{1}\right]$ is

$$
\begin{aligned}
& D C=C_{d}\left[\int_{0}^{\mu} \alpha \beta t^{\beta-1} Q(t) d t+\int_{\mu}^{t_{1}} \frac{\theta}{t} Q(t) d t\right] \\
& =C_{d}\left[\begin{array}{c}
\frac{1}{\theta+1}\left\{\left(t_{1}-\mu\right)+\frac{\theta_{1}^{\theta+1}}{\theta}\left(t_{1}^{-\theta}-\mu^{-\theta}\right)\right\} \\
+\frac{\lambda-\theta_{1}}{\theta+2}\left\{\frac{1}{2}\left(t_{1}^{2}-\mu^{2}\right)+\frac{t_{1}^{\theta+2}}{\theta}\left(t_{1}^{-\theta}-\mu^{-\theta}\right)\right\} \\
\beta+1
\end{array}-\theta a\left[\begin{array}{l}
\mu_{1}^{\beta+1} \\
\frac{\theta_{1}}{\theta+1}\left\{\frac{1}{2}\left(t_{1}^{2}-\mu^{2}\right)-\frac{t_{1}^{\theta+1}}{1-\theta}\left(t_{1}^{1-\theta}-\mu^{1-\theta}\right)\right\} \\
+\frac{\left(\lambda-\theta_{1}\right)}{\theta+2} \theta_{1}\left\{\frac{1}{3}\left(t_{1}^{3}-\mu^{3}\right)+\frac{t_{1}^{\theta+2}}{1-\theta}\left(t_{1}^{1-\theta}-\mu^{1-\theta}\right)\right\}
\end{array}\right]\right.
\end{aligned}
$$

\section{(3) Shortage Cost (SC)}

The cost of shortage during the interval $\left[t_{1}, T\right]$ is given by:

$$
\begin{aligned}
& S C=-C_{s}\left[\int_{t_{1}}^{t_{2}} Q(t) d t+\int_{t_{2}}^{T} Q(t) d t\right] \\
& =C_{s}\left[\begin{array}{l}
a\left\{\frac{1}{2}\left(t_{2}-t_{1}\right)^{2}+\frac{\lambda}{2}\left(\frac{1}{3}\left(t_{2}^{3}-t_{1}^{3}\right)-t_{1}^{2}\left(t_{2}-t_{1}\right)\right)\right\}+ \\
\left.(p-a) T-\frac{a \lambda}{2} T^{2}\right)\left(T-t_{2}\right)- \\
\frac{(p-a)}{2}\left(T^{2}-t_{2}^{2}\right)+\frac{a \lambda}{6}\left(T^{3}-t_{2}^{3}\right)
\end{array}\right]
\end{aligned}
$$

(4) Production Cost (PC)

The production cost per cycle is $P C=C_{p}\left[\mu+\left(T-t_{2}\right)\right] p$

$$
\begin{aligned}
& A M C=C_{a}\left[\int_{0}^{\mu} \theta_{1} Q(t) d t+\int_{\mu}^{t_{1}} \theta_{1} Q(t) d t\right] \\
& =C_{a} \theta_{1}\left[(p-a) \frac{\mu^{2}}{2}-a\left\{\begin{array}{c}
\frac{1}{2(\theta+1)}\left(t_{1}^{2}-\mu^{2}\right)-\frac{t_{1}^{\theta+1}}{1-\theta}\left(t_{1}^{1-\theta}-\mu^{1-\theta}\right) \\
+\frac{\lambda-\theta_{1}}{\theta+2}\left(\frac{1}{3}\left(t_{1}^{3}-\mu^{3}\right)-\frac{t_{1}^{\theta+2}}{1-\theta}\left(t_{1}^{1-\theta}-\mu^{1-\theta}\right)\right)
\end{array}\right\}\right]
\end{aligned}
$$

\section{(6) Inventory Holding Cost (IHC)}

The cost of holding the inventory over the time period $\left[0, t_{1}\right]$ is given by:

$$
I H C=\int_{0}^{\mu}(h+r t) Q(t) d t+\int_{\mu}^{t_{1}}(h+r t) Q(t) d t
$$

$$
=h\left[(p-a) \frac{\mu^{2}}{2}+\left\{(p-a) \theta_{1}+a \lambda\right\} \frac{\mu^{3}}{6}-\frac{(p-a) \alpha \beta}{(\beta+1)(\beta+2)} \mu^{\beta+2}\right]+
$$$$
r\left[(p-a) \frac{\mu^{3}}{3}+\left\{(p-a) \theta_{1}+a \lambda\right\} \frac{\mu^{4}}{8}-\frac{(p-a) \alpha \beta}{(\beta+1)(\beta+3)} \mu^{\beta+3}\right]-
$$$$
a\left[h\left[\begin{array}{l}
\frac{1}{\theta+1}\left\{\frac{1}{2}\left(t_{1}^{2}-\mu^{2}\right)-\frac{t_{1}^{\theta+1}}{1-\theta}\left(t_{1}^{1-\theta}-\mu^{1-\theta}\right)\right\}+ \\
\frac{\lambda-\theta_{1}}{\theta+2}\left\{\frac{1}{3}\left(t_{1}^{3}-\mu^{3}\right)-\frac{t_{1}^{\theta+2}}{1-\theta}\left(t_{1}^{1-\theta}-\mu^{1-\theta}\right)\right\}+ \\
\frac{\theta_{1}}{\theta_{1}+1}\left\{\frac{1}{3}\left(t_{1}^{3}-\mu^{3}\right)-\frac{t_{1}^{\theta+1}}{2-\theta}\left(t_{1}^{2-\theta}-\mu^{2-\theta}\right)\right\}+ \\
\frac{\lambda-\theta_{1}}{\theta+2} \theta_{1}\left\{\frac{1}{4}\left(t_{1}^{4}-\mu^{4}\right)-\frac{t_{1}^{\theta+2}}{2-\theta}\left(t_{1}^{2-\theta}-\mu^{2-\theta}\right)\right\}
\end{array}\right]\right]+
$$$$
\left[\begin{array}{l}
\frac{1}{\theta+1}\left\{\frac{1}{3}\left(t_{1}^{3}-\mu^{3}\right)-\frac{t_{1}^{\theta+1}}{2-\theta}\left(t_{1}^{2-\theta}-\mu^{2-\theta}\right)\right\}+ \\
\frac{\lambda-\theta_{1}}{\theta+2}\left\{\frac{1}{4}\left(t_{1}^{4}-\mu^{4}\right)-\frac{t_{1}^{\theta+2}}{2-\theta}\left(t_{1}^{2-\theta}-\mu^{2-\theta}\right)\right\}+
\end{array}\right]
$$$$
\left[\begin{array}{l}
\frac{\theta_{1}}{\theta_{1}+1}\left\{\frac{1}{4}\left(t_{1}^{4}-\mu^{4}\right)-\frac{t_{1}^{\theta+1}}{3-\theta}\left(t_{1}^{3-\theta}-\mu^{3-\theta}\right)\right\}+ \\
\frac{\lambda-\theta_{1}}{\theta+2} \theta_{1}\left\{\frac{1}{5}\left(t_{1}^{5}-\mu^{5}\right)-\frac{t_{1}^{\theta+2}}{3-\theta}\left(t_{1}^{3-\theta}-\mu^{3-\theta}\right)\right\}
\end{array}\right] \begin{aligned}
& \text { (15) } \\
& (16)
\end{aligned}
$$

\section{(5) Amelioration Cost (AMC)}

The amelioration cost over the period $\left[0, t_{1}\right]$ is 


\section{(7) Total Cost (TC)}

Hence, the average total cost for the period $[0, T]$ is given by

$T C=\frac{1}{T}[O C+D C+S C+A M C+P C+I H C]$

Using the expressions (12), $t_{2}$ is eliminated from equation (19) of total cost TC.

Hence, TC becomes a function of $\mu, t_{1}$ and $T$ only, which are the decision variables and have $\mu^{*}, t_{1}^{*}$ and $T^{*}$ as respective optimum values, which minimize the cost function $T C$ and they are the solutions of the equations $\frac{\partial T C}{\partial \mu}=0, \frac{\partial T C}{\partial t_{1}}=0$ and $\frac{\partial T C}{\partial T}=0$ such that

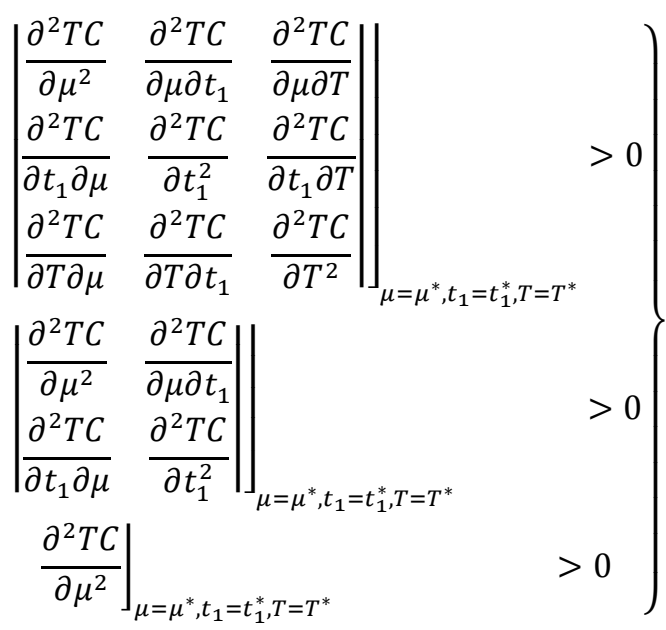

The optimal values $\mu^{*}, t_{1}^{*}$ and $T^{*}$ can be obtained with the help of a mathematical software.

\section{NUMERICAL EXAMPLE}

Below numerical illustration is used to demonstrate the above mentioned inventory model with the values of parameters being $A=400, p=4, a=2, \alpha=$ $0.0001, \beta=2, \lambda=0.0002, \theta=0.22, \theta_{1}=0.11, h=$

$8, r=4, C_{p}=10, C_{d}=2, C_{s}=8$ and $C_{a}=3 \quad$ (With appropriate units).

The optimal values of $\mu, t_{1}$ and $T$ are $\mu^{*}=1.063004997, t_{1}^{*}=3.729283836$ and $T^{*}=11.67971141$.The optimal total cost per unit time TC $=83.5993432$ units.

\section{SENSITIVITY ANALYSIS}

Sensitivity analysis is a technique to study the impact of variation in an independent variable's value, on a particular dependent variable. Here, we've tried to capture the sensitivity of TC per unit time for every change in the value of parameters $A, p, a, \lambda, \theta, \theta_{1}, h, r, C_{p}, C_{d}, C_{19}$ and $C_{a}$.

The below analysis is carried out by considering an increase and decrease variation of $10 \%$ and $20 \%$ for the value of each parameter, keeping other parameters static. The results are presented in the Table- 1 at the end and the last column shows the \% variation in $\mathrm{TC}$ as compared to the original value, for each of the parameter.

\section{GRAPHICAL RENDITION}

Graphical rendition facilitates presentation of data in a simple, clear and effective manner along with easy comparison of values, trends and relationships.

Graphical rendition of the sensitivity analysis is shown in Fig. 2 and Fig. 3 at the end.

\section{CONCLUSION}

- From the Table - 1, we observe that the parameters $A, p, a, \lambda, \theta, h, r, C_{p}, C_{d}, C_{s}$ and $C_{a}$ have a linear relationship with average total cost while the parameters $\alpha, \beta$ and $\theta_{1}$ have an inverse relation with average total cost.

- From Table-1 and Figure-2, a continuum scale is observed for the average total cost. On one hand it is highly sensitive by the values of $A, p, a, C_{p}, C_{s}$ and on the other hand it is less sensitive by the values of $\alpha, \beta, \lambda, \theta$ and $\theta_{1}$ and in between it shows the moderate sensitivity due to the values of $h, r, C_{d}$ and $C_{a}$.

- Figure -3 shows the effect of decision variables $t_{1}$ and $\mathrm{T}$ on average total cost TC.

\section{REFERENCES}

[1] Ankit Bhojak and U. B. Gothi., "Inventory Models for Ameliorating and Deteriorating Items with Time Dependent Demand and IHC" International Journal of Management and Social Science Research Review, Vol.1, Issue.2, 85 - 98, 2016. 
[2] Ankit Bhojak and U.B. Gothi. "Inventory Model for Ameliorating and Deteriorating Items with Time Dependent Demand" Sankhya Vignan, (NSV 11), No.2, 31- 43, 2015.

[3] Chun-Hsiung Lan, Yen-Chieh Yu, Robert H.-J. Lin, Cheng-Tan Tung, Chih-Pin Yen and Peter Shaohua Deng, "A Note on the Improved Algebric Method for the EPQ Model with Stochastic Lead Time," Information and Management Sciences Vol. 18, No.1, pp. 91-96, 2007.

[4] Devyani Chatterji, U.B.Gothi, "An EPQ Model for TwoParameter Weibully Deteriorated Items with Exponential Demand Rate and Completely Backlogged Shortages," International Journal of Computer Science Trends and Technology (IJCST) - Vol.3 Issue 6, Nov-Dec 2015.

[5] Hwang, H. S. "A study on an inventory models for items with Weibull ameliorating”. Computers \& Industrial Engineering 33, 701-704, 1997.

[6] Kapil Kumar Bansal and Navin Ahalawat, "Integrated Inventory Models for Decaying Items with Exponential Demand under Inflation," International Journal of Soft Computing and Engineering (IJSCE) Vol.2, Issue-3, 2012.

[7] Kawale S.V. and Bansode P.B., "An EPQ model using Weibull deterioration for deterioration item with time varying holding cost," International Journal of Science, Engineering and Technology Research, Vol.1, Issue 4, pp. 29-33, 2012.

[8] L. Tadj, A.M. Sarhan and A. EI-Gohary, "Optimal control of an inventorysystem with ameliorating and deteriorating items." Applied Sciences, 10,243-255, 2008.

[9] Madhu Jain, G.C. Sharma and Shalini Rathore, "Economic production quantity models with Shortage, price and stockdependent Demand for deteriorating items," IJE Transactions Vol. 20, No 2, pp. 159-166, 2007.
[10] Parmar, K.C. and Gothi U. B., "An EPQ model of deteriorating items using three parameter Weibull distribution with constant production rate and time varying holding cost." International Journal of Science, Engineering and Technology Research, Vol. 4, Issue 2, , pp. 409 - 416, 2015.

[11] Parmar, K.C. and Gothi, U.B., "EPQ model for deteriorating items under three parameter Weibull distribution and time dependent IHC with shortages." American Journal of Engineering Research, Vol. 4, Issue 7, pp. 246-255, 2015.

[12] Pooja Khatri and U. B. Gothi, "An Inventory Model of Deteriorating Items under Inflation and Discount Rate with Power Demand and Time Dependent Holding Cost", International Journal of Advanced Research in Science, Engineering and Technology, Vol. 4, Issue 3, March 2017.

[13] R. Shamsi, A. Haji, S. Shadrokh and F. Nourbakhsh, "Economic Production Quantity in Reworkable Production Systems with Inspection Errors, Scraps and Backlogging," Journal of Industrial and Systems Engineering Vol. 3, pp. 170-188, 2009.

[14] S.T. Law and H.M. Wee, "An integrated production-inventory forameliorating and deteriorating items taking account of time discounting ", Mathematical and Computer Modelling , 43, 673685,2006

[15] Srichandan Mishra, L.K.Raju, U.K.Misra \& G.Misra.. "Optimal Control of An Inventory System with Variable Demand \& Ameliorating / Deteriorating Items". Asian Journal of Current Engineering and Maths, 154 - 157. 2012.

[16] U. B. Gothi, Kareeshaa Shah and Pooja Khatri, "A two warehouse Inventory model with Weibull and Pareto Type-I deterioration and power demand, International" Journal of Research In Science \& Engineering, Vol.3 Issue.3, May-June 2017. 


\begin{tabular}{|c|c|c|c|c|c|c|}
\hline Parameter & value & $\mu$ & $t$ & $T$ & $T S$ & of hangr \\
\hline \multirow{4}{*}{$\boldsymbol{A}$} & 320 & $\frac{\boldsymbol{\mu}}{0.90033564}$ & $\frac{\boldsymbol{1}}{3.37818453}$ & $\frac{\mathbf{I}}{10.42297096}$ & $\frac{\text { IC }}{76.36011800}$ & -8.65943 \\
\hline & 360 & 0.98445439 & 3.55811830 & 11.06856661 & 80.08254075 & -4.20673 \\
\hline & 440 & 1.13692182 & 3.89371931 & 12.26222407 & 86.94079630 & 3.99698 \\
\hline & 480 & 1.20694417 & 4.05307250 & 12.82067221 & 90.13028023 & 7.81219 \\
\hline \multirow{4}{*}{$p$} & 3.2 & 1.68510190 & 3.96998028 & 13.32484524 & 76.02982817 & -9.05451 \\
\hline & 3.6 & 1.32483309 & 3.82530134 & 12.32591093 & 80.40914267 & -3.81606 \\
\hline & 4.4 & 0.86443037 & 3.66093525 & 11.22485952 & 86.03191370 & 2.90980 \\
\hline & 4.8 & 0.71049325 & 3.61048602 & 10.88680220 & 87.94851190 & 5.20240 \\
\hline \multirow{4}{*}{$a$} & 1.6 & 0.78249778 & 3.98594728 & 12.05730775 & 78.02626641 & -6.66641 \\
\hline & 1.8 & 0.91805924 & 3.83553875 & 11.80293555 & 81.12089002 & -2.96468 \\
\hline & 2.2 & 1.21895264 & 3.65845327 & 11.67660777 & 85.47100850 & 2.23885 \\
\hline & 2.4 & 1.38857960 & 3.61880868 & 11.79505107 & 86.72440848 & 3.73815 \\
\hline \multirow{4}{*}{$\alpha$} & 0.00008 & 1.06300928 & 3.72928677 & 11.67971332 & 83.59933492 & -0.00001 \\
\hline & 0.00009 & 1.06301371 & 3.72928999 & 11.67971619 & 83.59933213 & -0.00001 \\
\hline & 0.00011 & 1.06302258 & 3.72929644 & 11.67972193 & 83.59932656 & -0.00002 \\
\hline & 0.00012 & 1.06302701 & 3.72929966 & 11.67972481 & 83.59932381 & -0.00002 \\
\hline \multirow{4}{*}{$\beta$} & 1.99998 & 1.06301815 & 3.72929321 & 11.67971906 & 83.59932933 & -0.00002 \\
\hline & 1.99999 & 1.06301815 & 3.72929321 & 11.67971906 & 83.59932933 & -0.00002 \\
\hline & 2.00001 & 1.06301815 & 3.72929321 & 11.67971906 & 83.59932935 & -0.00002 \\
\hline & 2.00002 & 1.06301815 & 3.72929321 & 11.67971906 & 83.59932934 & -0.00002 \\
\hline Parameter & value & $\mu$ & $t_{1}$ & $T$ & $T C$ & \%change \\
\hline \multirow{4}{*}{ 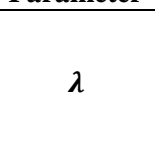 } & 0.00016 & 1.06328013 & 3.73023461 & 11.68012342 & 83.59589190 & -0.00413 \\
\hline & 0.00018 & 1.06314908 & 3.72976372 & 11.67992081 & 83.59761137 & -0.00207 \\
\hline & 0.00022 & 1.06288733 & 3.72882309 & 11.67951819 & 83.60104579 & 0.00204 \\
\hline & 0.00024 & 1.06275662 & 3.72835333 & 11.67931818 & 83.60276081 & 0.00409 \\
\hline \multirow{4}{*}{$\boldsymbol{\theta}$} & 0.176 & 1.03028526 & 3.79932558 & 11.71221551 & 83.29964711 & -0.35849 \\
\hline & 0.198 & 1.04709177 & 3.76355345 & 11.69551181 & 83.45188675 & -0.17638 \\
\hline & 0.242 & 1.07814752 & 3.69642986 & 11.66475678 & 83.74225060 & 0.17094 \\
\hline & 0.264 & 1.09255074 & 3.66486121 & 11.65055412 & 83.88090017 & 0.33679 \\
\hline \multirow{4}{*}{$\theta_{1}$} & 0.088 & 1.03512956 & 3.53953269 & 11.53697018 & 83.97425802 & 0.44847 \\
\hline & 0.099 & 1.04517512 & 3.61995356 & 11.59647145 & 83.80740392 & 0.24888 \\
\hline & 0.121 & 1.09429945 & 3.88855742 & 11.80559316 & 83.33312996 & -0.31844 \\
\hline & 0.132 & 1.15755626 & 4.16557942 & 12.03709923 & 82.97049260 & -0.75222 \\
\hline \multirow{4}{*}{$\boldsymbol{h}$} & 6.4 & 1.04807325 & 3.93570953 & 11.74443919 & 82.46780392 & -1.35353 \\
\hline & 7.2 & 1.05904828 & 3.83118965 & 11.71284804 & 83.05019244 & -0.65688 \\
\hline & 8.8 & 1.06198296 & 3.63045374 & 11.64585771 & 84.11818967 & 0.62063 \\
\hline & 9.6 & 1.05728453 & 3.53487467 & 11.61177843 & 84.60926082 & 1.20804 \\
\hline \multirow{4}{*}{$\boldsymbol{r}$} & 3.2 & 1.18134056 & 4.12366095 & 11.94172428 & 82.54313582 & -1.26342 \\
\hline & 3.6 & 1.11686839 & 3.90792896 & 11.79632000 & 83.10429844 & -0.59216 \\
\hline & 4.4 & 1.01686296 & 3.57721726 & 11.58310543 & 84.04193745 & 0.52942 \\
\hline & 4.8 & 0.97656544 & 3.44516009 & 11.50115613 & 84.44183207 & 1.00777 \\
\hline \multirow{4}{*}{$C_{p}$} & 8 & 1.21718857 & 3.73280447 & 11.74581137 & 80.09004223 & -4.19776 \\
\hline & 9 & 1.14192968 & 3.73243839 & 11.71582479 & 81.85804944 & -2.08290 \\
\hline & 11 & 0.98056505 & 3.72341070 & 11.63740292 & 85.31281093 & 2.04962 \\
\hline & 12 & 0.89503411 & 3.71505920 & 11.58901327 & 86.99743701 & 4.06474 \\
\hline \multirow{4}{*}{$C_{d}$} & 1.6 & 1.05364556 & 3.72739550 & 11.67431598 & 83.57130969 & -0.03353 \\
\hline & 1.8 & 1.05837161 & 3.72836340 & 11.67704169 & 83.58536046 & -0.01673 \\
\hline & 2.2 & 1.06758815 & 3.73018645 & 11.68234986 & 83.61321788 & 0.01660 \\
\hline & 2.4 & 1.07208443 & 3.73104453 & 11.68493571 & 83.62702844 & 0.03312 \\
\hline \multirow{4}{*}{$C_{s}$} & 6.4 & 0.95552064 & 3.49588180 & 12.68464086 & 78.80451790 & -5.73548 \\
\hline & 7.2 & 1.01225053 & 3.61829584 & 12.13630556 & 81.32574004 & -2.71964 \\
\hline & 8.8 & 1.10883179 & 3.83079656 & 11.29311182 & 85.66431863 & 2.47009 \\
\hline & 9.6 & 1.15047720 & 3.92428207 & 10.96126485 & 87.55112101 & 4.72704 \\
\hline \multirow{4}{*}{$C_{a}$} & 2.4 & 1.06237673 & 3.74013736 & 11.68312084 & 83.53989853 & -0.07111 \\
\hline & 2.7 & 1.06270453 & 3.73470980 & 11.68142037 & 83.56966106 & -0.03551 \\
\hline & 3.3 & 1.06331778 & 3.72388761 & 11.67801698 & 83.62890360 & 0.03536 \\
\hline & 3.6 & 1.06360365 & 3.71849296 & 11.67631417 & 83.65838449 & 0.07062 \\
\hline
\end{tabular}




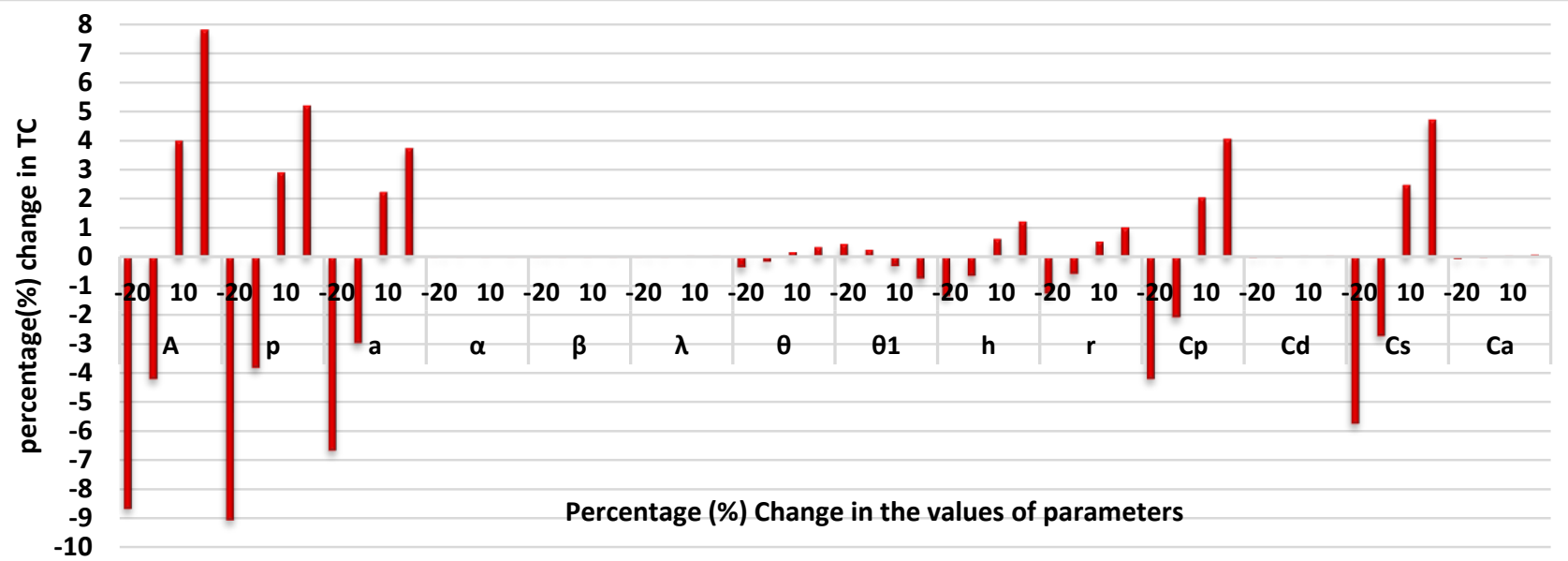

Fig. 2 : Graphical rendition of the sensitivity analysis

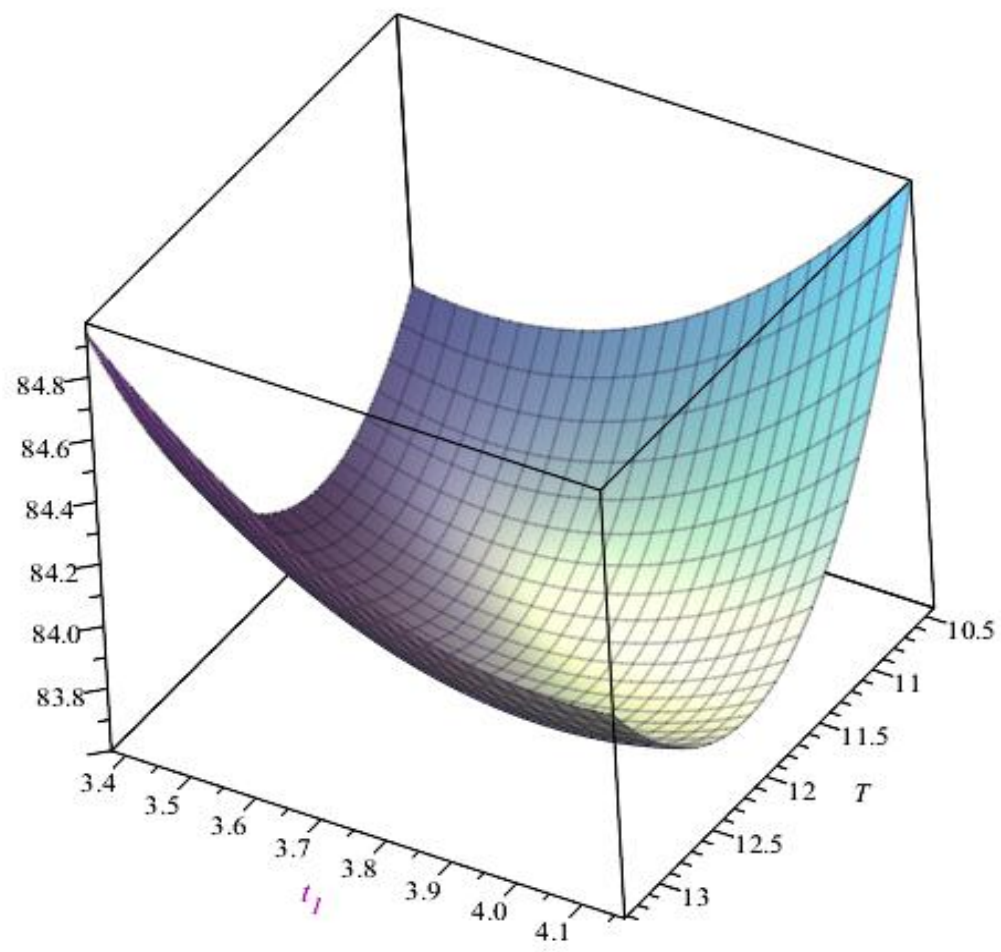

Fig. 3: 